This item was submitted to Loughborough's Research Repository by the author.

Items in Figshare are protected by copyright, with all rights reserved, unless otherwise indicated.

\title{
One night's CPAP withdrawal in otherwise compliant OSA patients: marked driving impairment but good awareness of increased sleepiness
}

PLEASE CITE THE PUBLISHED VERSION

http://dx.doi.org/10.1007/s11325-011-0588-8

PUBLISHER

(c) Springer-Verlag

VERSION

SMUR (Submitted Manuscript Under Review)

\section{LICENCE}

CC BY-NC-ND 4.0

\section{REPOSITORY RECORD}

Filtness, Ashleigh J., Louise A. Reyner, and James A. Horne. 2019. "One Night's CPAP Withdrawal in Otherwise Compliant OSA Patients: Marked Driving Impairment but Good Awareness of Increased Sleepiness". figshare. https://hdl.handle.net/2134/15408. 
This item was submitted to Loughborough's Institutional Repository (https://dspace.lboro.ac.uk/) by the author and is made available under the following Creative Commons Licence conditions.

\section{creative
commons}

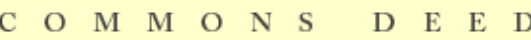

Attribution-NonCommercial-NoDerivs 2.5

You are free:

- to copy, distribute, display, and perform the work

Under the following conditions:

Attribution. You must attribute the work in the manner specified b the author or licensor.

Noncommercial. You may not use this work for commercial purposes.

No Derivative Works. You may not alter, transform, or build upon this work.

- For any reuse or distribution, you must make clear to others the license terms of this work.

- Any of these conditions can be waived if you get permission from the copyright holder.

Your fair use and other rights are in no way affected by the above.

This is a human-readable summary of the Leqal Code (the full license).

\section{Disclaimer 만}

For the full text of this licence, please go to: http://creativecommons.org/licenses/by-nc-nd/2.5/ 


\title{
One night's CPAP withdrawal in otherwise compliant OSA patients: marked driving impairment but good awareness of increased sleepiness
}

\section{Filtness $\mathrm{AJ}^{12 *}$, Reyner $\mathrm{LA}^{1}$ \& Horne $\mathrm{JA}^{1}$}

\author{
1. Sleep Research Centre \\ Loughborough University \\ Leicestershire LE11 3TU, UK \\ Phone+ 44(0)1509-22 8225 \\ $\mathrm{Fax}+44(0) 1509-228480$
}

2. Now at. Accident Research Centre

Monash Injury Research Institute

Monash University

Building 70

Clayton, Victoria, 3800

Australia

+61399020198

ashleigh.filtness@monash.edu

*corresponding author

$23^{\text {rd }}$ August 2011 


\section{ABSTRACT}

Purpose: OSA patients effectively treated by and compliant with CPAP occasionally miss a night's treatment. The purpose of this study was to use a real car interactive driving simulator to assess the effects of such an occurrence on the next day's driving, including the extent to which these drivers are aware of increased sleepiness.

Methods: 11 long-term compliant CPAP treated 50-75y male OSA participants completed a $2 \mathrm{~h}$ afternoon, simulated, realistic monotonous drive in an instrumented car, twice, following one night: i) normal sleep with CPAP ii) nil CPAP. Drifting out of road lane ('incidents'), subjective sleepiness every 200sec and continuous EEG activities indicative of sleepiness and compensatory effort were monitored.

Results: Withdrawal of CPAP markedly increased sleep disturbance, and led to significantly more incidents, a shorter 'safe' driving duration, increased alpha and theta EEG power and greater subjective sleepiness. However, increased EEG beta activity indicated more compensatory effort was being applied. Importantly, under both conditions there was a highly significant correlation between subjective and EEG measures of sleepiness, to the extent that participants were well aware of the effects of nil CPAP

Conclusions: Patients should be aware that compliance with treatment every night is crucial for safe driving.

\section{Keywords}

Driving performance, subjective sleepiness, EEG, obstructive sleep apnoea, CPAP, CPAP withdrawal. 


\section{INTRODUCTION}

Patients with obstructive sleep apnoea (OSA), treated by continuous positive air pressure (CPAP), have a level of driving performance that is comparable with that of controls [1], and in many countries are permitted to drive once successfully treated. However, polysomnographic studies have shown that withdrawal of CPAP in compliant users even for one night results in resumption of sleep disordered breathing, followed by immediate recovery on restarting treatment $[2,3]$. Despite knowing the importance of treatment, even the most compliant CPAP users report occasionally missing treatment for one night, stating reasons such as, 'have a cold' or 'away from home and unable to take the machine'. Few studies have assessed this temporary effect on driving ability.

For safety reasons, no real road driving studies have assessed this effect of CPAP withdrawal, and with the few driving simulation studies, only simple simulators have been utilised. These lack realism, typically using a replica steering wheel linked to a computer-based tracking task displayed on a computer screen. Using such a task, Turkington et al. [4] reported impaired tracking ability following CPAP withdrawal, although performance did not fall as low as pre-treatment levels. However, the test only lasted $20 \mathrm{~min}$, which is too short a duration to reveal the full effect of sleepiness, and does not typify many driving situations, especially as sleepiness only becomes particularly evident during monotonous drives beyond $20 \mathrm{~min}$ (eg. [5,6]). Moreover, realistic fullscale interactive driving simulators involving an interactive real car, further add to the realism and, arguably, provide more valid data.

Although some laboratory studies have utilised simple performance measures, such as the PVT, in assessing acute CPAP withdrawal effects (eg. [3,7,]), such tests only last around 10 min and are of limited comparability with much longer and more realistic periods of driving. Similarly, whilst sleep onset findings with the multiple sleep latency test (MSLT) show significant reductions after one night of CPAP withdrawal (eg. [8]), this test involves participants lying down in a darkened room and encouraged to go to sleep, which clearly contrasts with the driver who has to stay awake under somewhat more stimulating conditions.

The present study had two aims. First, to assess the extent to which sustained driving performance in a full size interactive and realistic driving simulator can be maintained following one night of CPAP withdrawal in otherwise successfully treated participants having OSA. The second aim comes from evidence that sufferers with OSA may have a distorted self awareness of sleepiness when driving, at least before treatment [9]. In the light of this, a novel aspect of this study is to determine the extent to which those who have been successfully treated by CPAP might underestimate sleepiness whilst driving, after a night without CPAP. 


\section{METHOD}

\subsection{Participants}

OSA participants were recruited from a regional sleep apnoea patients association, all of whom had been undergoing CPAP treatment for an average of 7.8y. All were men aged between 50 and 75 years, had Epworth sleepiness scale (ESS) [10] scores $<10$ and drove $>3 \mathrm{~h}$ per week. Initial selection was by structured interview, including questions relating to health, medication, sleep, driving and OSA, as well as caffeine intake. This was followed by measurements of height, weight and percentage body fat calculated using a body composition analyzer TBF-300 (TANITA Corporation). They were then given a familiarisation drive. This study was part of a larger investigation involving sleep restriction in patients and healthy controls [11]. Participants were asked if they would also be prepared to go without CPAP for another night so that we could make further comparisons. Eleven agreed to participate in this component of the study. Further details of these 11 participants can be seen in Table 1. For all experimental phases (see below), participants were collected from and returned to home via taxi and advised not to drive or undertake any potentially hazardous activities until they had a full night's sleep with CPAP. They were given a small cash gift on completion. The study met with the full approval of the University's Ethical Committee.

\subsection{Design \& Procedure}

The study consisted of two conditions:

1. a normal night's sleep with CPAP

2. a night's sleep without CPAP

To ensure compliance with sleep instructions, participants wore wrist actimeters (Cambridge Neurotechnology, UK) for three nights prior to each experimental day, when they also kept daily logs of: estimated sleep onset, and morning wakening and rising times. As well as sleep duration, sleep quality was assessed by calculating sleep disturbance index (SDI)

$$
\mathrm{SDI}=\text { actual awake time }(\mathrm{min}) / \text { assumed total sleep }(\mathrm{min})
$$

No alcohol was consumed 36h prior to each drive, and nil caffeine after 18:00h the evening before. Participants refrained from eating after 10:00h on the morning of the drive, and had consumed only a light breakfast. On arrival at the laboratory, at 13:00h, they were given a light lunch of two cheese rolls and a glass of water. Actimeters were downloaded to verify that they had complied with the previous night's sleep requirements. At 13:15h electrodes were applied and they went to the simulator (see below) at 13:50h, to be given $10 \mathrm{~min}$ to settle into the car, the $2 \mathrm{~h}$ drive began at 4 
14:00h. Participants were instructed to drive in the left hand lane (unless overtaking) at a speed appropriate for the road and where full control of the vehicle could be maintained. During the drive the investigator remained in the room, out of sight, but there was no communication once the drive had begun.

\subsection{Apparatus}

2.3.1 Car Simulator - This comprises an immobile car with a full-size, interactive, computer generated road projection of a dull monotonous dual carriageway, each with two lanes. The image is projected onto a $2.0 \mathrm{~m} \times 1.5 \mathrm{~m}$ screen, located $2.3 \mathrm{~m}$ from the car windscreen. The road has a hard shoulder and simulated auditory 'rumble strips' (incorporated into white lane markings) either side of the carriageway, with long straight sections followed by gradual bends. 'Crash barriers' are located either side, beyond the rumble strips. Slow moving vehicles are met occasionally, which have to be overtaken. Lane drifting is the most common manifestation of sleepy driving; occasions where all four wheels of the car cross the left rumble strip or right side lane line are identified as a driving 'incident' (in the UK driving is on the left side of the road). Split-screen video footage of the roadway and driver's face (filmed by an unobtrusive infrared camera) enable the cause of the incident to be determined. Those due to sleepiness (e.g. eye closure, eyes rolling upwards or vacant staring ahead) are logged as a 'sleep-related incident'. As a further check for the latter, the electroencephalogram (EEG) and electrooculogram (EOG - see below) are examined respectively for alpha/theta intrusions and confirmation of any 'eye rolling'. Non-sleep related incidents (driver distraction, fidgeting or looking around) are excluded.

2.3.2 Subjective Sleepiness - Every 200s during the drive, participants were verbally prompted by the computer system to report their subjective sleepiness, and their numerical response was based on the 9-point Karolinska Sleepiness Scale (KSS): 1=extremely alert, 2=very alert, 3=alert, 4=rather alert, $5=$ neither alert nor sleepy, $6=$ some signs of sleepiness, $7=$ sleepy, no effort to stay awake, 8=sleepy, some effort to stay awake, 9=very sleepy, great effort to keep awake, fighting sleep. The scale was located on the car's dashboard and continuously visible to the driver. This prompting and its response quickly became routine for the driver.

2.3.3 EEG and EOG - Electrodes were attached for two channels of EEG, with inter-electrode distances carefully maintained by using the '10-20 EEG montage' (main channel $C_{3}-A_{1}$, backup channel $C_{4}-A_{2}$ ), and there were two EOG channels (electrodes $1 \mathrm{~cm}$ lateral to and below left outer canthus and $1 \mathrm{~cm}$ lateral to and above right outer canthus; both referred to the centre of the forehead). EEGs and EOGs were recorded using "Embla" (Flaga Medica Devices, Iceland) and spectrally analysed using "Somnologica" (Flaga) in 4s epochs. EEG low and high band-pass filtering at $>20 \mathrm{~Hz}$ and $<4 \mathrm{~Hz}$ removed slow eye movements and muscle artefacts. In these 
circumstances, greater EEG power in the alpha $(8-11 \mathrm{~Hz})$ and theta $(4-7 \mathrm{~Hz})$ ranges reflect increased sleepiness [12-14], whereas increased beta activity $(13-20 \mathrm{~Hz})$ indicates increased arousal, anxiety and mental effort, suggestive of trying to stay awake [15-17]. EEG power in 4-11 $\mathrm{Hz}$ (theta+alpha) was averaged in one minute epochs, as was beta activity $(13-20 \mathrm{~Hz})$. To accommodate for individual differences in EEG power, and to allow comparisons between conditions, each individual's power in these ranges was standardised for each condition, by taking the difference between each minute's epoch and the individual's mean value over the first 30min of the normal sleep with CPAP condition, then divide this by the standard deviation around the mean of that 30min of data [18]. This can mean that when $4-11 \mathrm{~Hz}$ power is particularly low, values may appear to be negative (as was the case with initial driving after normal sleep - see Figures 4 and $6)$.

\subsection{Statistical Analyses}

Repeated measures analysis of variance (ANOVA) were utilised, with two within subject factors: Condition - (two levels: normal sleep and CPAP withdrawal); Duration of driving (four levels: 0-30 min, 30-60min, 60-90min and 90-120min). Where appropriate square root transformations corrected for skewed driving incident raw data. Repeated measures $t$ tests were applied to other overall group differences.

\section{RESULTS}

3.1 Total sleep time and SDI. There was no significant difference between sleep duration between the two conditions. Withdrawal of CPAP significantly increased SDI from 7.9 after a normal night's sleep to 13.8 without CPAP [t(10) $=3.5, \mathrm{p}<0.05-$ two tail].

3.2 Driving incidents (Figure 1) - Following CPAP withdrawal there were significantly more incidents $[F(1,20)=12.33, p<0.05]$ and, as might be expected there was a significant rise in incidents over the duration of the drive, over both conditions $[F(3,30)=4.75, p<0.05]$, but no significant interaction.

3.3 Time to first incident ('safe driving time') (Figure 2) - After normal sleep participants drove for an average of 90min (s.e. 9min). Following CPAP withdrawal this decreased to 50min (11min) resulting in a significant difference between conditions $[t(10)=3.8, p<0.05]$

3.3 Subjective Sleepiness - KSS (Figure 3 - mean changes per $200 \mathrm{sec}$ ). When data were collapsed into $30 \mathrm{~min}$ epochs there was a significant effect of condition $[F(1,10)=24.12, p<0.05]$, and duration of drive $[F(3,30)=69.03, p<0.05]$. The interaction between condition and drive 
duration was also significant $[F(3,30)=5.03, p<0.05]$, with CPAP withdrawal having a greater effect during the first hour.

3.4 EEG - Theta + Alpha Power (Figure 4 - mean values per min). There was no significant difference between conditions when data were collapsed into 30 min epochs $[F(1,10)=1.82, p=$ 0.207], but there was a significant overall effect of drive duration $[F(3.30)=6.03, p, 0.05]$. Interestingly, though, just before the mean onset of the first driving incident under CPAP withdrawal, between minutes 45-50, there was a surge in this power compared with normal sleep; a one tail t-test $[\mathrm{t}(10)=1.87, \mathrm{p}<0.05-$ one tail].

3.5 EEG - Beta Power (Figure 5 - mean values per min). When data were collapsed into 30 min epochs, there was a significant between conditions effect $[F(1,10)=4.0, p=0.05]$ indicating that participants were applying more compensatory effort after CPAP withdrawal. There was also an overall significant effect of drive duration $[F(3,30)=3.56, p<0.05]$, but no significant interaction.

3.6 Correlation between Theta + Alpha Power and KSS (Figure 6). Figure 6 makes the direct comparison for CPAP withdrawal, and when these EEG data are collapsed into 200sec epochs and correlated with KSS data, the outcome was indeed highly significant [ $r=0.88$, df $34 ; p<0.000]$, and likewise for the normal sleep condition [r=0.87, df 34; $p<0.000]$.

\section{DISCUSSION}

Our participants experienced significantly more sleep disturbance during CPAP withdrawal, despite a comparable total sleep times. This indicates a resumption of sleep disordered breathing; a finding in line with those from CPAP withdrawal studies using full PSG recordings $[2,3]$.

One night without CPAP significantly worsened sleepiness and driving performance in long term treated compliant CPAP users. A significant reduction (by $40 \mathrm{~min}$ ) in 'safe driving time' was also evident after CPAP withdrawal, with the first incident being portended by a marked rise in alpha+theta activity $5 \mathrm{~min}$ beforehand. However, participants remained subjectively quite aware of their increased sleepiness (as determined objectively by EEG). Moreover, under both sleep conditions there was a highly significant association between these two measures of sleepiness. This level of self-awareness of increasing sleepiness when driving is similar to what we have found with a group of healthy drivers of a similar age (mean age 66.6y [52-74y]) having undergone sleep restriction [11], and in young male adult drivers [19,20].

The incidents occurring on the simulator are indicative of dangerous driving, which is not to say that a collision is imminent or that an incident would occur at this time on a real road, as the more evident dangers of real driving would probably have enabled our participants to have driven safely 
for longer on real roads. Nevertheless there is good evidence that simulators such as ours do reflect real driving conditions [21], and it remains likely that following CPAP withdrawal driving performance would be impaired because of the obvious increase in daytime sleepiness.

Our study has shortcomings especially as participant selection may have been biased, as they were also self-selected from the original group of 19. All of the latter had been asked if they had ever missed a nights treatment, and all those reporting 'yes' to this question happened to decline to participate in this extra component of CPAP withdrawal and were absent from the 11 volunteers. It is a reoccurring problem in this type of study, as Yang et al [2] noted "individuals who are compliant CPAP users may be reluctant to volunteer for this type of research if they have previously experienced marked negative symptoms with CPAP withdrawal." The withdrawal of the CPAP treatment may have influenced the participant's subjective reports of sleepiness. An alternative approach would have been to provide sham (non therapeutic) CPAP so that participants would not be aware that they had not received treatment that night. The current protocol was designed to represent occasions when patients may miss a nights treatment due to reasons such as being away from home and not taking the machine with them, on such occasions patients would be aware that they had not used the treatment and as such withdrawal of treatment in our study allows us to assess the impact this would have.

Ours was a study designed to highlight the risk of missing one night's CPAP treatment in compliant users. However many OSA patients use their CPAP for only part of a night, and we have yet to determine to what extent this might impact on driving ability.

OSA patients need to know that even if they are generally fully compliant with treatment, CPAP withdrawal is likely to increase sleepiness and impair driving to a greater degree than might be anticipated, especially on monotonous roads and during the afternoon bi-circadian trough.

\section{ACKNOWLEDGEMENTS}

We wish to thank all of the participants and Leicester Sleep Apnoea Patients Association for their co-operation with recruitment, additionally Dr Chris Hanning and Dr Andrew Hall from Leicester General Hospital Sleep Disorders Services, University Hospitals of Leicester NHS Trust, for their continued support.

\section{CONFLICT OF INTEREST}

The authors declare that they have no conflict of interest. 


\section{REFERENCES}

[1] George C (2001) Reduction in motor vehicle collisions following treatment of sleep apnoea with nasal CPAP. Thorax 56:508-512.

[2] Grunstein RR, Stewart DA, Lloyd H, Akinci M, Cheng N, Sullivan CE (1996) Acute withdrawal of nasal CPAP in obstructive sleep apnea does not cause a rise in stress hormones. Sleep 19:10:774-782.

[3] Yang Q, Phillips CL, Melehan KL, Rogers NL, Seale JP, Grunstein RR (2006) Effects of shortterm CPAP withdrawal on neurobehavioral performance in patients with obstructive sleep apnea. Sleep 29:4:545-552.

[4] Turkington PM, Sircar M, Saralaya D, Elliott MW (2004) Time course of changes in driving simulator performance with and without treatment in patients with sleep apnoea hypopnoea syndrome. Thorax 59:1:56-59.

[5] Horne JA, Reyner LA (1995) Sleep related vehicle accidents BMJ 310:6979:565-567.

[6] Horne JA, Reyner LA (1999) Vehicle accidents related to sleep: a review BMJ 56:5:289-294.

[7] Kribbs NB, Pack AI, Kline LR, Getsy JE, Schuett JS, Henry JN, Maislin G, Dinges DF (1993) Effects of one night without nasal CPAP treatment on sleep and sleepiness in patients with obstructive sleep apnea Am. Rev. Resp. Dis.147:5:1162-1168.

[8] Sforza E, Lugaresi E (1995) Daytime sleepiness and nasal continuous positive airway pressure therapy in obstructive sleep apnea syndrome patients: effects of chronic treatment and 1-night therapy withdrawal. Sleep 18:3:195-201.

[9] Engleman HM, Hirst WS, Douglas NJ (1997) Under reporting of sleepiness and driving impairment in patients with sleep apnoea/hypopnoea syndrome. J Sleep Res 6:272-5.

[10] Johns MW (1991) A new method for measuring daytime sleepiness: the Epworth Sleepiness Scale. Sleep14:540-546. 
[11] Filtness AJ, Reyner LA, Horne JA (2011) Moderate sleep restriction in treated older male OSA participants: greater impairment during monotonous driving compared with controls. Paper in press.

[12] Ákerstedt T, Gillberg M (1990) Subjective and objective sleepiness in the active individual. Int J Neurosci 52:29-37.

[13] Kecklund G, Åkerstedt T (1993) Sleepiness in long distance truck driving: An ambulatory EEG study of night driving. Ergonomics 36:1007-1017.

[14] Eoh H, Chung M, Kim S (2005) Electroencephalographic study of drowsiness in simulated driving with sleep deprivation. Int J Ind Ergon 35:307-320.

[15] Greneche J, Krieger J, Erhardt C, Bonnefond A, Eschenlauer A, Muzet A, Tassi P(2008) EEG spectral power and sleepiness during $24 \mathrm{~h}$ of sustained wakefulness in patients with obstructive sleep apnea syndrome. Clin Neurophysiol 119:418-428.

[16] Tassi P, Grenčche J, Pebayle T, Eschenlauer A, Hoeft A, Bonnefond A, Rohmer O, Muzet A (2008) Are OSAS patients impaired in their driving ability on a circuit with medium traffic density? Accid Anal Prev 40:1365-1370.

[17] Jap B, Lal S, Fischer P, Bekiaris E (2009) Using EEG spectral components to assess algorithms for detecting fatigue. Expert Syst Appl 36:2352-2359.

[18] Horne J, Reyner L (1996) Counteracting driver sleepiness: effects of napping, caffeine, and placebo. Psychophysiology 33:306-309.

[19] Reyner LA, Horne JA (1998) Falling asleep at the wheel: are drivers aware of prior sleepiness? Int J Legal Med 111:120-123.

[20] Horne JA, Baulk SD (2003) Awareness of sleepiness when driving. Psychophysiology 41:161165.

[21] Philip P, Sagaspe P, Taillard J, Valtat C, Moore N, Akerstedt T, Charles A, Bioulac B (2005) Fatigue, sleepiness, and performance in simulated versus real driving conditions. Sleep 28:1511-6. 
Table 1 Participant characteristics - mean and standard error

Fig. 1 Driving incidents in 30 minute epochs - mean and standard error. There was a significant effect of CPAP withdrawal.

Fig. 2 Number of minutes until first driving incident - mean and standard error. There was a significant effect of CPAP withdrawal.

Fig. 3 Mean KSS scores every 200 seconds. There were significant effects for between conditions, and significant interaction with time on task.

Fig. 4 Mean standardised theta+alpha $(4-11 \mathrm{~Hz})$ EEG power in 1 min epoch (smoothed by 3 point running average). There was a significant effect of drive duration, although no significant overall effect of condition.

Fig. 5 Mean standardised beta $(13-20 \mathrm{~Hz})$ EEG power in 1 min epochs (smoothed by 3 point running average). There was a significant effect of condition with more beta power following CPAP withdrawal.

Fig. 6 Comparison of KSS with standardised EEG theta + alpha following CPAP withdrawal. The two measures are significantly correlated. 
Table 1

\begin{tabular}{|l|l|}
\hline $\mathrm{N}=11$ & Mean \\
\hline AGE $(\mathrm{y})$ & $65.6(2.3)$ \\
\hline BMI & $33.1(1.8)$ \\
\hline \% FAT & $32.5(2.1)$ \\
\hline ESS & $5.2(0.7)$ \\
\hline $\begin{array}{l}\text { USUAL SLEEP (min } \\
\text { actimeter) }\end{array}$ & $465(3.6)$ \\
\hline $\begin{array}{l}\text { SLEEP baseline (min } \\
\text { actimeter) }\end{array}$ & $436(4.0)$ \\
\hline $\begin{array}{l}\text { SLEEP CPAP withdrawal } \\
\text { (min actimeter) }\end{array}$ & $403(3.6)$ \\
\hline
\end{tabular}

Figure 1

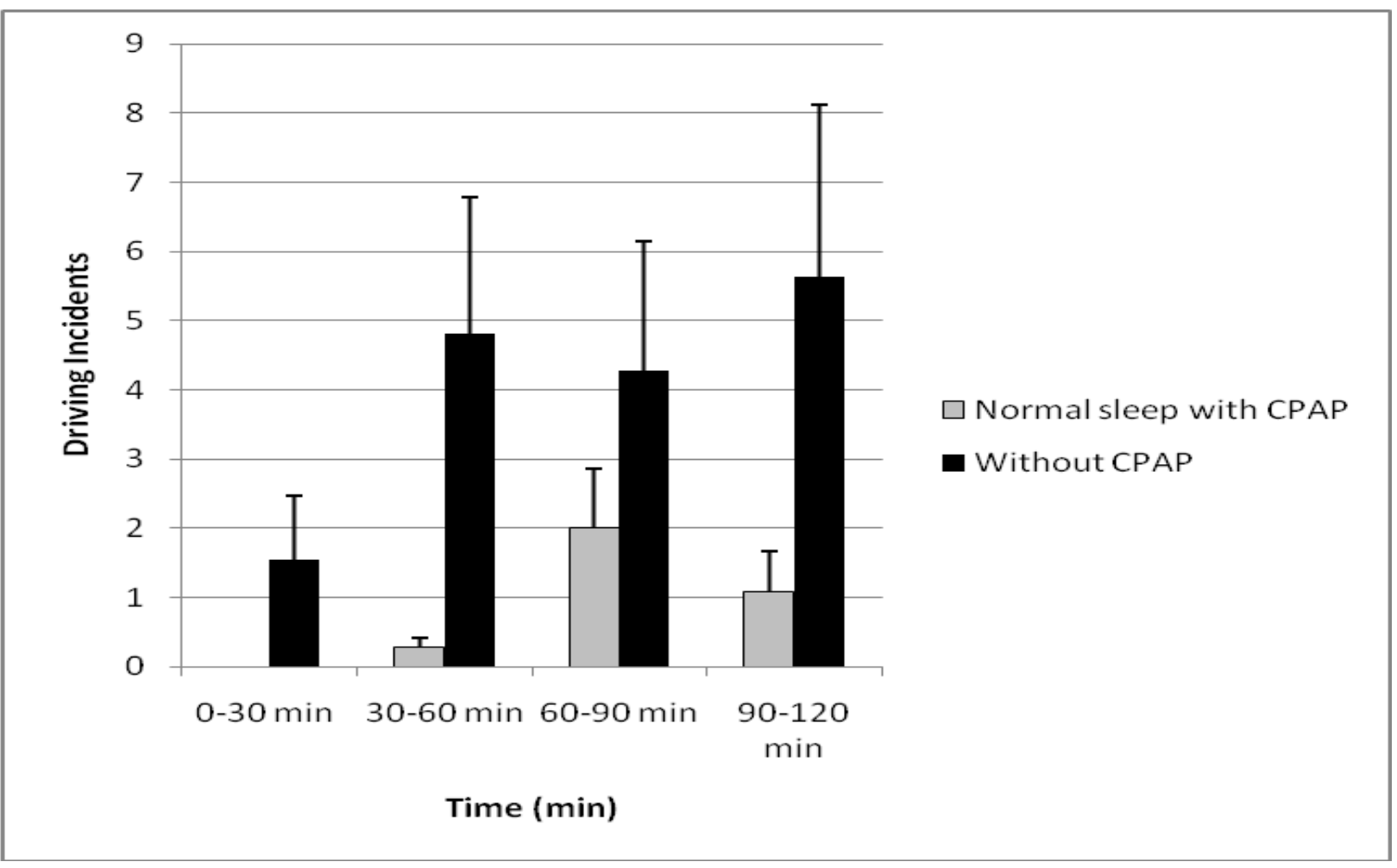


Figure 2

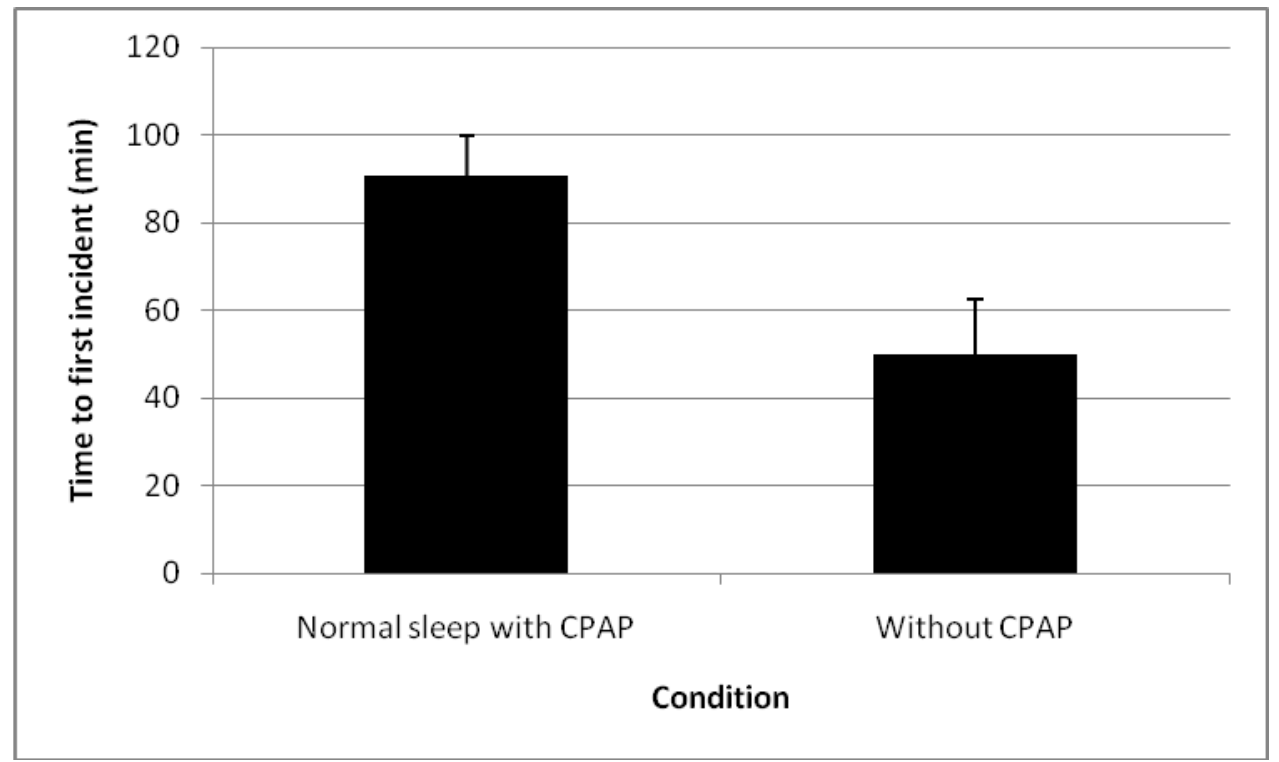

Figure 3

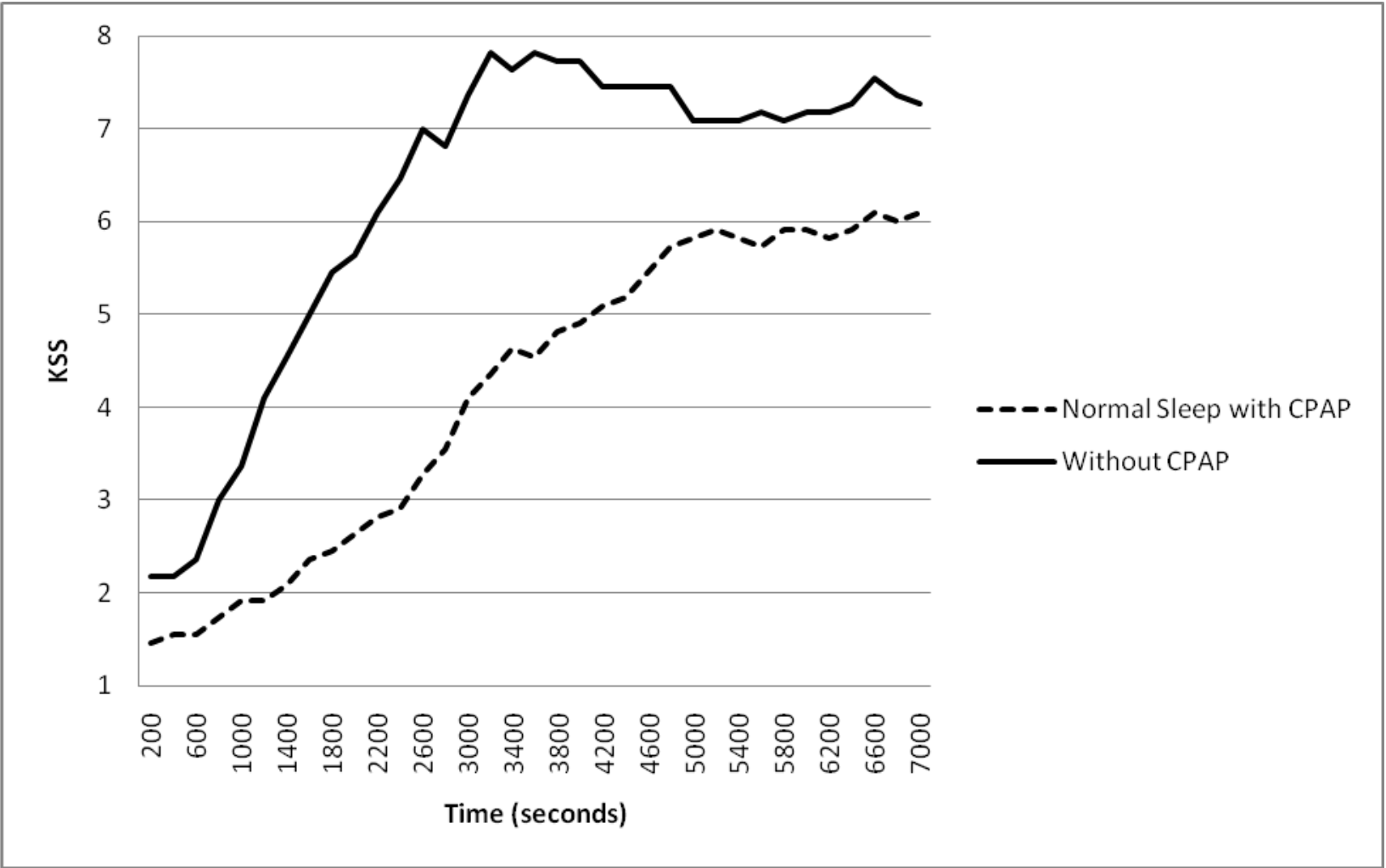


Figure 4

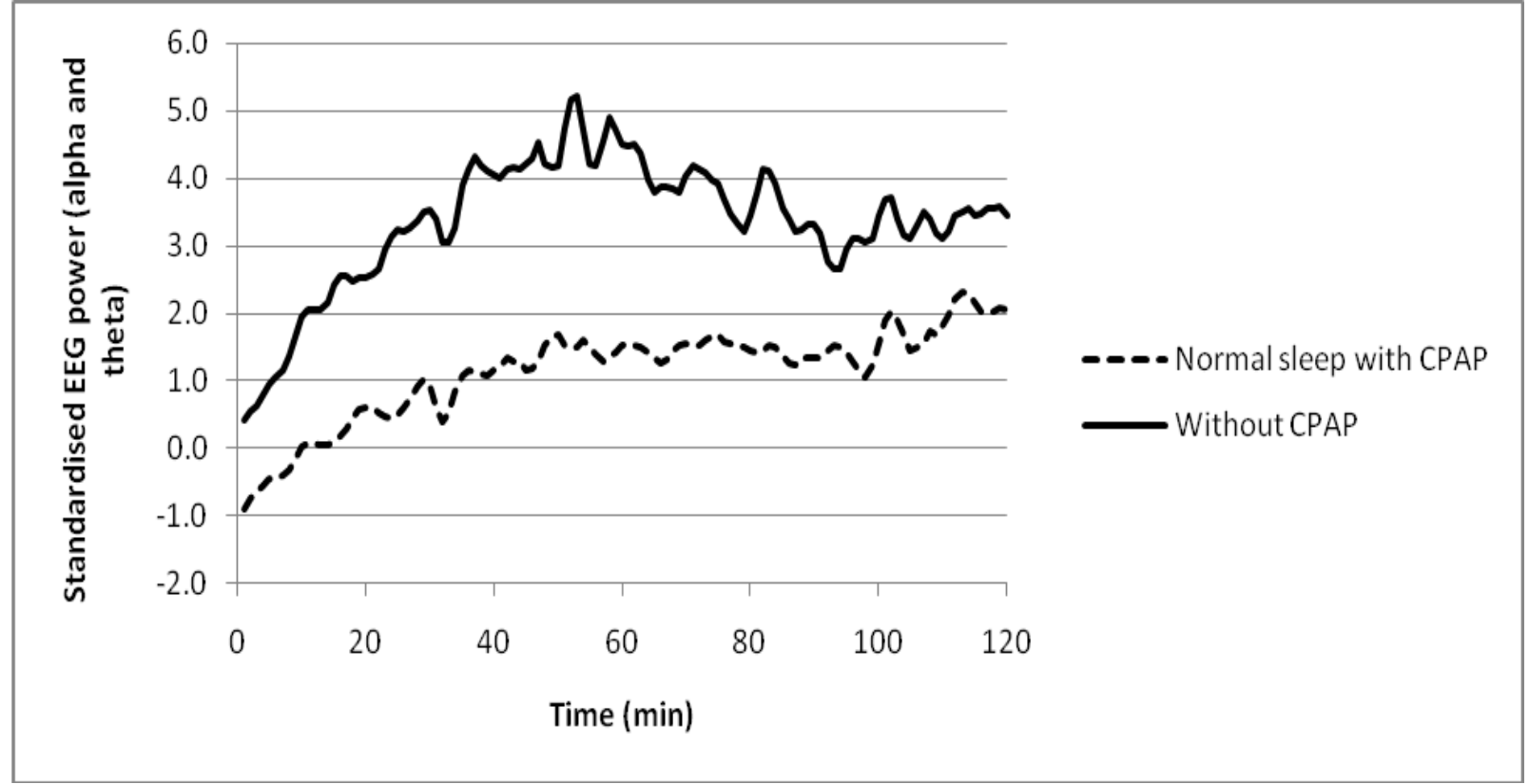

Figure 5

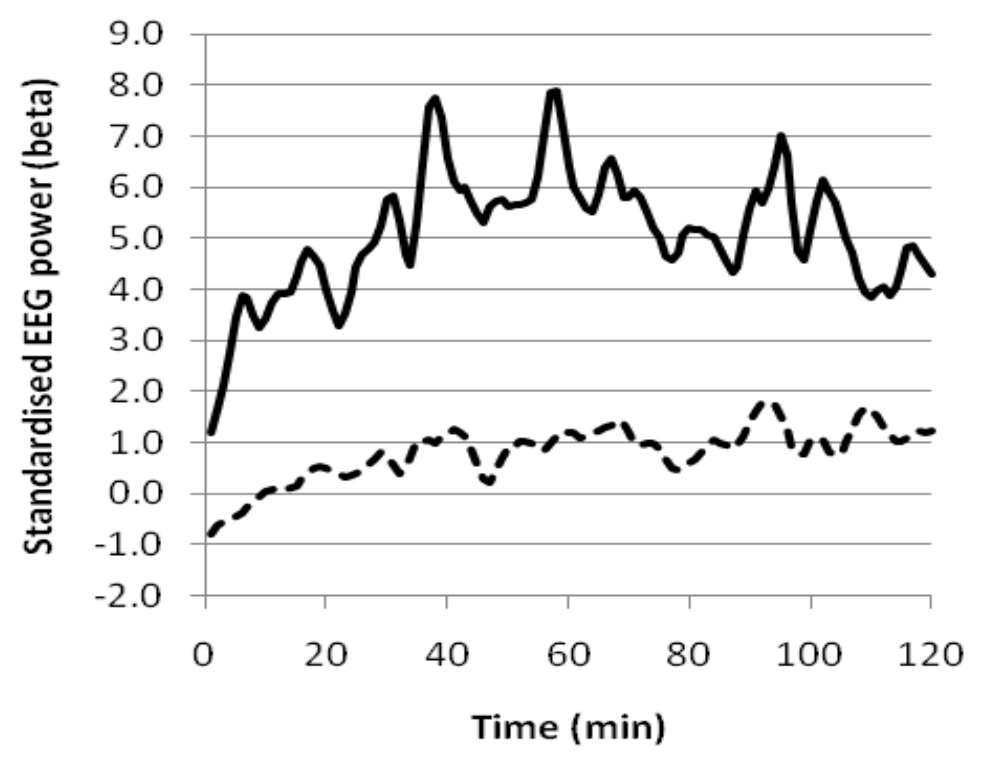

Normal sleep with CPAP

Without CPAP 
Figure 6

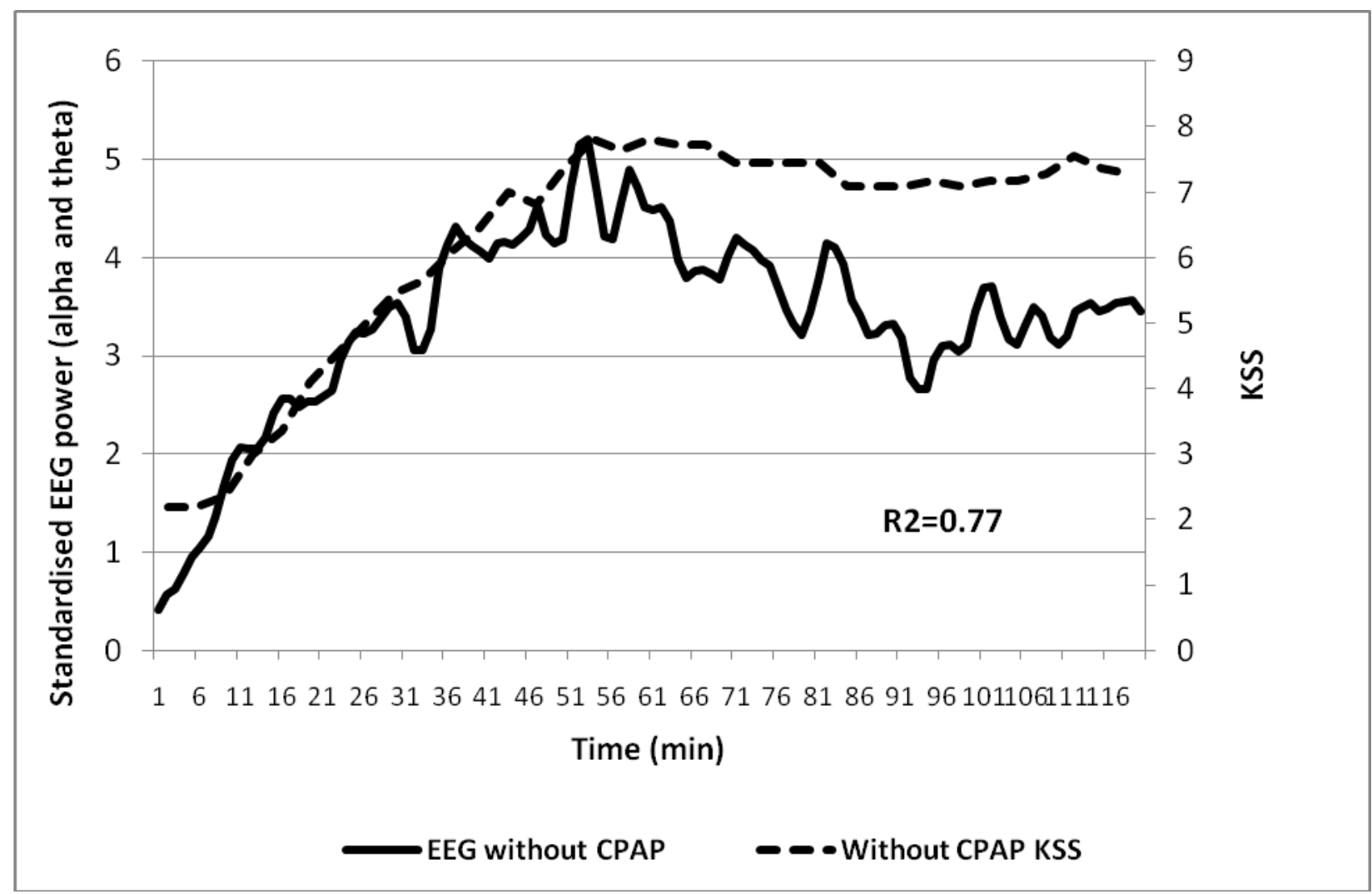

